\title{
PENGUKURAN EFEKTIVITAS MESIN PRODUKSI GULA DI PG KREMBOONG SIDOARJO
}

\section{Measurement of The Effectiveness of Sugar Production Machines in PG Kremboong Sidoarjo}

\author{
Miftakhurrizal Kurniawan*, Wahyu Agung Rizal Ramadhan, Usman Effendi \\ Jurusan Teknologi Industri Pertanian - Fakultas Teknologi Pertanian -Universitas Brawijaya \\ Jl. Veteran - Malang 65145 \\ Penulis Korespondensi, email : miftakhurrizal@ub.ac.id
}

Disubmit : 26 Oktober $2020 \quad$ Direvisi : 13 April $2021 \quad$ Diterima : 16 April 2021

\begin{abstract}
ABSTRAK
PG Kremboong merupakan salah satu perusahaan gula pasir di bawah naungan PTPN X yang sudah berusia 172 tahun. Kegiatan produksi yang berjalan secara terus-menerus dan umur pabrik yang sudah sangat tua menjadi salah satu faktor yang dapat menyebabkan penurunan efektivitas mesin produksi. Oleh karena itu, penelitian ini bertujuan untuk mengukur tingkat efektivitas mesin produksi gula terutama di stasiun gilingan PG Kremboong dan memberikan alternatif strategi perbaikan. Metode yang digunakan pada penelitian ini yaitu overall throughput effectiveness (OTE), fishbone diagram, dan analytical hierarchy process (AHP). Metode OTE digunakan untuk mengukur tingkat efektivitas stasiun giling PG Kremboong dan six big losses pada setiap mesinnya. Fishbone diagram digunakan untuk mengetahui faktor yang berpengaruh. Metode AHP digunakan untuk menentukan tingkat prioritas perbandingan berpasangan antar faktor, subfaktor dan alternatif strategi perbaikan. Hasil penelitian menunjukkan nilai OTE sebesar $84,41 \%$ dengan bottleneck indicator sebesar 0,0256 . Rata-rata kerugian yang terjadi pada setiap mesin yaitu breakdown losses $0,048 \%$, setup and adjustment losses $0,159 \%$, idle and minor stoppages $12,127 \%$, dan reduced speed losses $11,749 \%$. Faktor yang menjadi prioritas utama pada metode AHP yaitu material $(0,543)$, method $(0,275)$, machine $(0,118)$ dan man $(0,063)$. Prioritas alternatif strategi perbaikan untuk meningkatkan efektivitas stasiun giling di PG Kremboong terdiri atas perbaikan perencanaan produksi $(0,606)$, peningkatan pengawasan dan pengecekan mesin $(0,234)$, dan memberikan pelatihan perbaikan mesin $(0,161)$
\end{abstract}

Kata Kunci : AHP; Fishbone diagram; OTE

\begin{abstract}
PG Kremboong is a sugar company under the auspices of PTPN X which is 172 years old. Production activities that are running continuously and the age of the factory is very old to be one of the factors that can cause a decrease in the effectiveness of production machines. Therefore, this study aims to measure the level of effectiveness of sugar production machines, especially at the PG Kremboong mill station, and provide alternative improvement strategies. The methods used in this study are overall throughput effectiveness (OTE), fishbone diagram, and analytical hierarchy process (AHP). The OTE method is used to measure the effectiveness level of the PG Kremboong mill and six big losses on each machine. A Fishbone diagram is used to determine the influencing factors. AHP method is used to determine the priority level of pairwise comparisons between factors, sub-factors, and alternative improvement strategies. The results showed that the OTE value was $84.41 \%$ with a bottleneck indicator of 0.0256 . The average losses that occurred on each machine were $0.048 \%$ breakdown losses, $0.159 \%$ setup and adjustment losses, $12.127 \%$ idle and minor stoppages, and $11.749 \%$ reduced speed losses. The main priority factors in the AHP method are material (0.543), method (0.275), machine (0.118), and man (0.063). The priority of alternative improvement strategies to increase the effectiveness of the milling station at $P G$ Kremboong consists of improving production planning (0.606), increasing monitoring and checking machines (0.234), and providing machine repair training (0.161).
\end{abstract}

Keywords : AHP; Fishbone diagram; OTE 


\section{PENDAHULUAN}

Gula kristal putih berbasis tebu di Indonesia diproduksi oleh 62 unit pabrik dengan rincian 50 unit dikelola BUMN dan 12 pabrik swasta. PG Kremboong merupakan salah satu perusahaan gula pasir di bawah naungan PTPN X. Terhitung sejak 1847 hingga 2019, PG Kremboong sudah berusia 172 tahun. Kegiatan produksi yang berlangsung di PG Kremboong sepenuhnya dikerjakan oleh mesin yang berlangsung selama 24 jam dan terbagi dalam 3 shift kerja. Musim giling tebu di PG Kremboong berlangsung selama 4 bulan, mulai bulan April sampai Agustus. Kegiatan produksi yang berjalan secara terus-menerus dan umur pabrik yang sudah sangat tua menjadi salah satu faktor yang dapat menyebabkan penurunan efektivitas mesin produksi. Pada kegiatan proses produksi terkadang produk yang dihasilkan tidak tepat waktu dan juga tidak memenuhi permintaan yang diterima oleh perusahaan. Banyak faktor yang menyebabkan hal tersebut bisa terjadi, salah satunya yaitu kinerja mesin produksi kurang maksimal yang disebabkan oleh beberapa hal seperti downtime (kehilangan waktu operasional) pada mesin dan keandalan mesin yang menurun.

Salah satu stasiun yang perlu diperhatikan perbaikannya adalah stasiun gilingan. Pada stasiun ini dilakukan pemisahan antara nira dengan ampas tebu. Proses pemisahan ini dilakukan dengan menggunakan mesin dalam beberapa proses dimulai dari pemindahan tebu ke meja tebu yang akan dibawa menuju cane cutter untuk dicacah, setelah itu tebu ditumbuk pada mesin unigrator dan kemudian digiling di mesin giling untuk diambil niranya. Oleh karena itu peran mesin, seperti cane cutter, mesin unigrator dan mesin giling, sangat penting dalam proses produksi gula (Rochim dan Iskandar, 2015). Pada PG Kremboong, stasiun ini hampir setiap minggunya terjadi kerusakan mesin yang menyebabkan berhentinya proses penggilingan sehingga dapat menghambat proses produksi. Kerusakan-kerusakan pada mesin tersebut seringkali disebabkan karena mesin mengelami kelebihan muatan dan perbedaan kualitas tebu juga dapat memacu terjadinya kerusakan mesin. Hal ini dapat menurunkan tingkat efektivitas dan efisiensi mesin serta menimbulkan tambahan biaya perbaikan yang dapat merugikan perusahaan.

Metode overall throughput effectiveness (OTE) merupakan salah satu metode pengukuran efektivitas mesin produksi yang dikembangkan berdasarkan ide untuk membandingkan antara produktivitas aktual dengan produktivitas maksimum yang dapat dicapai menurut perusahaan. OTE dikembangkan untuk masingmasing subsistem yang telah ditentukan. OTE juga menyumbang subsistem yang memproses banyak produk dan melakukan pengerjaan ulang. OTE berpotensi untuk mengotomatiskan seluruh diagnostik kinerja tingkat pabrik, sehingga mendorong peningkatan produktivitas berkelanjutan secara kuantitatif. Konsep OTE muncul sebagai pengembangan OEE untuk mengukur efektivitas dari sistem produksi. Pada konsep OTE ini suatu sistem dipandang sebagai suatu kesatuan subsistem (Hardiyansyah dan Singgih, 2012; Schiraldi et al., 2020; Tayal et al., 2021). Hasil OTE nanti akan dianalisis menggunakan diagram fishbone agar dapat mengetahui akar penyebab dari penurunan efektivitas mesin di stasiun giling. Diagram fishbone akan menghasilkan beberapa usulan perbaikan dari penyebab permasalahan yang terjadi. Solusi-solusi tersebut nantinya diolah menggunakan metode analytical hierarchy process (AHP) agar mendapatkan solusi prioritas perbaikan. Penelitian ini bertujuan untuk mengukur tingkat efektivitas mesin produksi gula terutama di stasiun gilingan dengan menggunakan OTE, menentukan akar penyebab permasalahan menggunakan metode diagram fishbone dan memberikan alternatif strategi perbaikan menggunakan metode AHP.

\section{METODE}

Penelitian ini dilakukan di PG Kremboong yang terletak di Jl. PG Krembung No.31, Kremboong Timur, Krembung, Kec. Krembung, Kabupaten Sidoarjo, Jawa Timur 61275. Penelitian dilaksanakan pada bulan Maret-Mei 2020.

Metode yang digunakan dalam penelitian ini adalah menggunakan metode overall throughput effectiveness (OTE), fishbone diagram dan analytical hierarchical process (AHP). Penelitian ini dimulai dari melakukan survei pendahuluan, studi literatur, mengidentifikasi dan merumuskan masalah, mengumpulkan data, mengolah data, menyusun diagram fishbone, menentukan alternatif strategi perbaikan mesin, kesimpulan dan saran. Alur penelitian dapat dilihat pada Gambar 1. 


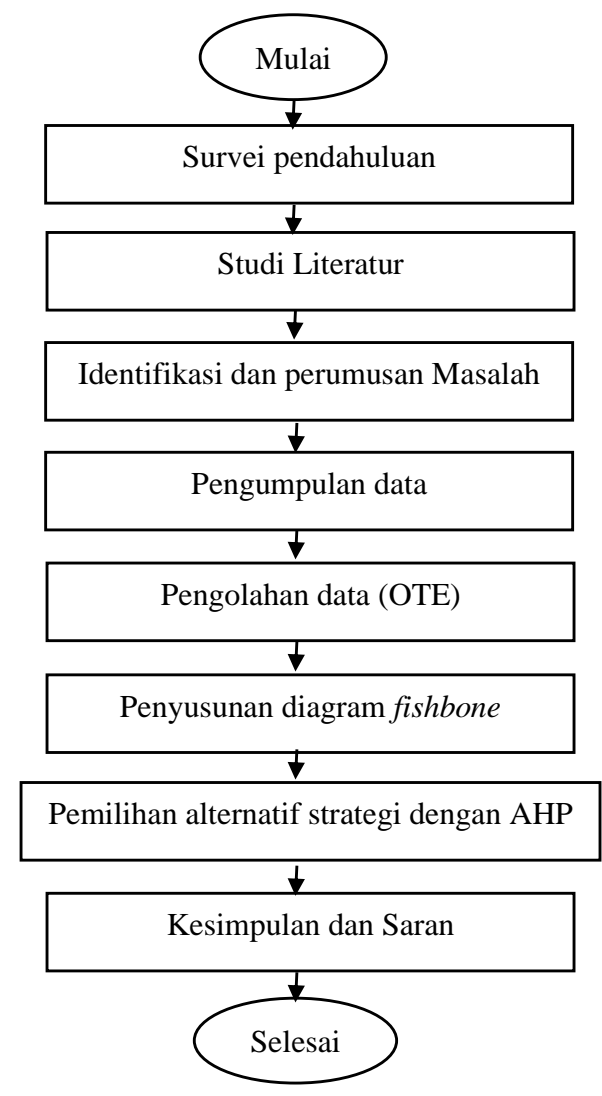

Gambar 1. Alur penelitian

Sumber data yang digunakan dalam penelitian ini terdiri dari dua jenis data, yaitu data primer dan sekunder.

\section{a. Data primer}

Data primer merupakan data yang diperoleh dari hasil pengamatan secara langsung yang dilakukan di PG Kremboong. Data primer dapat berupa hasil observasi terhadap suatu benda, kejadian atau kegiatan, dan hasil pengujian.

\section{b. Data sekunder}

Data sekunder yang dibutuhkan meliputi profil PG Kremboong, visi dan misi perusahaan, diagram alir proses produksi, spesifikasi mesin, waktu yang tersedia untuk produksi (running time), waktu berhenti yang direncanakan (planned down time), waktu beroperasi (loading time), waktu kerusakan mesin (downtime), lama mesin beroperasi (operating time), siklus ideal (ideal cycle time), jumlah nira kotor (process amount), jumlah cacat (defect amount), equipment failure losses, setup and adjusment losses, idle and minor stoppage losses, reduce speed, losses defect dan losses reduce yield. Data tersebut didapatkan dari arsip/dokumentasi perusahaan yang berfungsi sebagai penunjang data primer.
Langkah-langkah pengolahan data adalah sebagai berikut.

\section{Perhitungan nilai availability rate (AR)}

Availability rate (AR) merupakan perhitungan antara waktu operasi dengan waktu loading. AR adalah ketersediaan mesin beroperasi atau tingkat pemanfaatan peralatan produksi. Perhitungan AR sesuai Persamaan (1).

$\mathrm{AR}=\frac{\text { operating } \text { Time }}{\text { Loading } \text { Time }} \times 100 \%$

\section{Perhitungan performance efficiency (PE)}

Performance efficiency (PE) adalah tingkat efektifitas kegiatan produksi, dimana jumlah produk yang dihasilkan dikalikan dengan waktu siklus ideal terhadap waktu operasi mesin. Perhitungan PE sesuai Persamaan (2).

$\mathrm{PE}=\frac{\text { Processed amount } x \text { Theoritical cycle time }}{\text { Operating time }} \times 100 \%$

3. Perhitungan rate of quality product (RQP) Rate of quality product (RQP) merupakan perbandingan produk berdasarkan kualitas yang dihasilkan. Perhitungan RQP berdasarkan jumlah input dan jumlah cacat produk (defect amount). Perhitungan RQP sesuai Persamaan (3).

$\mathrm{Q}_{\mathrm{eff}}=\frac{\text { Processed amount }- \text { defect amount }}{\text { Processed amount }} \times 100 \%$

\section{Perhitungan OEE}

Perhitungan OEE dilakukan berdasarkan hasil perhitungan availability rate, performance rate dan rate of quality. Hasil ketiga perhitungan tersebut kemudian dilakukan perkalian satu sama lain. Perhitungan OEE sesuai dengan Persamaan (4).

$\mathrm{OEE}=\mathrm{AR} \times \mathrm{PE} \times \mathrm{RQ}$

\section{Perhitungan OTE}

Perhitungan OTE didasarkan pada jenis subsistem atau jaringan yang digunakan pada mesin produksi. Proses produksi pada stasiun gilingan menggunakan sistem seri, sehingga perhitungan OTE sesuai dengan Persamaan (5).

Series $=$ $\frac{\min \left\{\min _{i=1,2, \ldots, n=1}\left\{\operatorname{OEE}_{(i)} X R_{t h(i)} X \prod_{j=i+1}^{n} Q_{e f f(j)}\right\}, O E E_{(n)} X R_{t h(n)}\right\}}{\min _{i=1,2, \ldots, n}\left\{R_{t h(i)}\right\}}$ 


\section{Downtime losses}

Downtime losses merupakan waktu yang terbuang sia-sia. Terdapat 2 macam kerugian di dalamnya yaitu :

a) Equipment failure losses (EFL), merupakan kerugian yang diakibatkan oleh kerusakan mesin produksi seperti mati mendadak, mesin terbakar, patah, longgar dan lain lain. Perhitungan EFL sesuai dengan Persamaan (6).

Breakdown losses $(\%)=\frac{\text { breakdown time }}{\text { loading time }} \times 100 \%$

b) Setup and adjusment losses (SAL), merupakan kerugian karena terjadi kerusakan setelah mesin dilakukan setup atau adanya lama waktu yang tercuri akibat setup mesin. Perhitungan (SAL) sesuai dengan Persamaan (7).

Setup and Adjusment Losses $=$ $\frac{\text { Setup and ad jusment losses }}{\text { loading time }} \times 100 \%$

\section{7. $\quad$ Speed losses}

Speed losses merupakan suatu kejadian dimana kecepatan produksi mengalami penurunan kecepatan sehingga produksi tidak mencapat target yang diinginkan. Speed losses terdiri dari 2 macam kerugian, yaitu :

a) Idle and minor stoppage losses (IMSL), merupakan suatu kejadian di mana mesin berhenti sesaat yang dapat diakibatkan oleh bahan baku yang terlambat atau pemadaman listrik. Perhitungan IMSL sesuai dengan Persamaan (8).

$I M S L=$

$\frac{\text { (jumlah target }- \text { jumlah produksi) } x \text { ideal cycle time }}{\text { loading time }} \times$

$100 \%$

b) Reduce speed losses (RSL), merupakan kerugian yang terjadi karena penurunan kecepatan mesin sehingga mesin tidak dapat beroperasi dengan maksimal. Perhitungan RSL sesuai dengan Persamaan (9).
$R S L=$

$\underline{(\text { Actual cycle time-ideal cycle time }) \times \text { total produk diproses }} \times$ loading time

$100 \%$

\section{Quality losses}

Quality losses merupakan suatu kejadian di mana produk yang dihasilkan tidak sesuai dengan standar yang diinginkan oleh perusahaan. Terdapat 2 macam quality losses, yaitu :

a) Defect losses, kerugian dikarenakan produk mengalami cacat saat keluar dari sistem produksi. Perhitungan Defect Losses sesuai dengan Persamaan (10).

$$
\text { Defect losses }=\frac{\text { Total reject } x \text { ideal cycle time }}{\text { loading time }} \times
$$$$
100 \%
$$

b) Reduce yield, merupakan kerugian pada awal waktu produksi di mana produk yang dihasilkan belum sesuai standar karena mesin belum pada kondisi stabil. Perhitungan Reduce Yield sesuai dengan Persamaan (11).

\section{Reduce yield $=$ $\frac{\text { ideal cycle time } x \text { jumlah cacat awal produksi }}{\text { loading time }} \times 100 \%$}

\section{HASIL DAN PEMBAHASAN}

\section{Proses Produksi Gula}

Proses pabrikasi gula atau proses produksi gula bertujuan untuk mendapat rendemen gula setinggi mungkin dengan memaksimalkan penggunaan nira. Secara umum proses produksi gula pada melalui beberapa tahapan, yaitu penggilingan tebu, pemurnian nira, penguapan nira, kristalisasi atau proses pemasakan, pemisahan, dan pengeringan serta pengemasan (Cahyati et al., 2011). Mesin-mesin di pabrik gula dikelompokkan berdasarkan proses pembuatan gula yang terbagi ke dalam 7 stasiun kerja, yaitu stasiun gilingan, pemurnian, penguapan, masakan, pendinginan, puteran dan pengemasan (Subiyanto, 2014). Untuk lebih jelasnya, proses produksi gula dapat dilihat pada Gambar 2. 


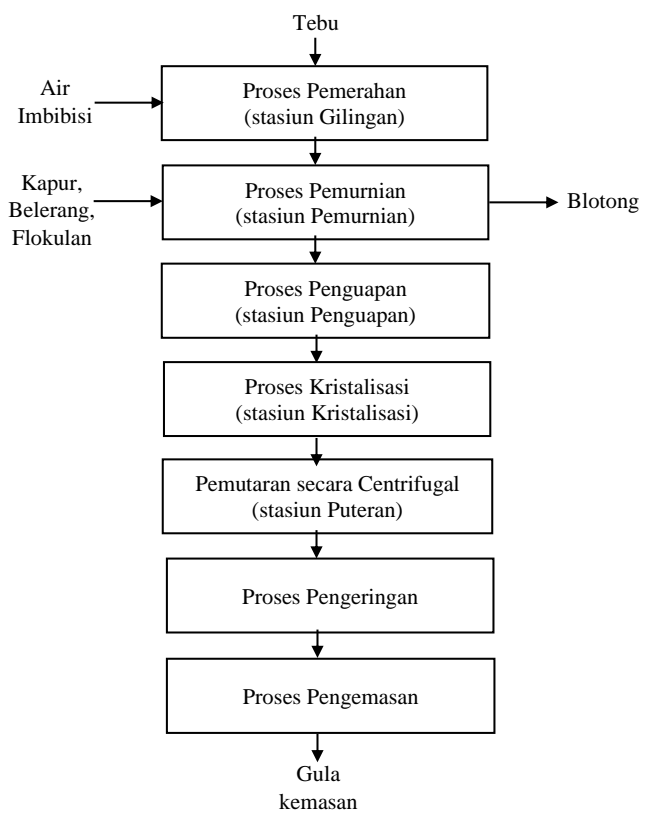

Gambar 2. Diagram alir proses produksi gula

\section{Data Total Downtime}

Downtime merupakan waktu yang terbuang karena produksi tidak berjalan seperti biasanya yang dikarenakan kerusakan oleh mesin (Maknunah et al., 2016). Faktor yang menyebabkan terjadinya downtime diakibatkan oleh faktor luar dan dalam. Faktor luar yaitu bahan baku yang kualitasnya berbeda-beda dan faktor dalam yaitu komponen mesin yang mengalami kerusakan karena pemakaian.

Berdasarkan data downtime mesin pada Tabel 1, terdapat 5 mesin yang mengalami downtime, yaitu meja tebu, cane cutter I, cane cutter II, mesin giling II dan mesin giling IV. Penyebab downtime pada mesin cane cutter I dan II adalah kondisi pisau pemotong yang sudah aus.

\section{Data Ideal Cycle Time (ICT) dan Actual Cycle Time (ACT)}

Ideal cycle time adalah waktu ideal mesin (menit) untuk melakukan proses produksi dalam 1 ton tebu (menit/ton). Sedangkan actual cycle time adalah waktu sebenarnya pada mesin (menit) untuk melakukan proses produksi dalam 1 ton (menit/ton). Data ICT dan ACT dari masing-masing mesin dapat dilihat pada Tabel 2.

Data hasil perhitungan total time available, planned downtime, loading time, operating time, ICT dan processed amount disajikan pada Tabel 3 . Hasil perhitungan $A_{\text {eff, }} P_{\text {eff, }} Q_{\text {eff, dan }}$ OEE dapat dilihat pada Tabel 4. Selanjutnya, perhitungan OTE ditunjukkan pada Persamaan (12). Nilai
OTE stasiun giling PG Kremboong sebesar $84,41 \%$ yang berarti hasil tersebut masih berada di bawah 85\%. Menurut Sitompul dan Rinawati (2019), Penetapan nilai standar tersebut dilakukan oleh Japan Institute of Plant Maintenance (JIPM). Nilai $60 \%-85 \%$ sudah dianggap wajar namun masih menunjukkan adanya bagian perlu diperbaiki. Sedangkan nilai 85\%-100\% sudah dianggap kelas dunia. Maka, hasil perhitungan OTE stasiun giling PG Kremboong sebesar $84,41 \%$ sudah dianggap wajar bahkan mendekati produksi kelas dunia, namun masih menunjukkan ruang yang dapat diperbaiki.

\section{Analisa Six Big Losess}

Six big losses adalah enam kerugian mesin/peralatan yang dapat menyebabkan rendahnya kinerja dari mesin dan peralatan, sehingga 6 kerugian tersebut perlu dihindari oleh setiap perusahaan (Nakajima, 1988; Chikwendu et al., 2020). Rendahnya kinerja mesin/peralatan tersebut dapat diakibatkan oleh umur mesin yang sudah tua sehingga mudah rusak, bahan baku yang telat datang, sehingga penggunaan mesin tidak efektif dan efisien.

Berdasarkan perhitungan yang sudah dilakukan maka diketahui jika rata-rata kerugian yang terjadi pasda setiap mesin yaitu breakdown losses 0,048\%, setup and adjustment losses 0,159\%, idle and minor stoppages $12,127 \%$, dan reduced speed losses $11,749 \%$.

\section{Analisis Kegagalan Menggunakan Diagram Fishbone \\ Diagram fishbone atau diagram tulang ikan} merupakan salah satu metode dalam menganalisis sebab-akibat suatu permasalahan. Diagram fishbone berguna untuk mengidentifikasi serta mengorganisir penyebab yang mungkin muncul dari suatu kejadian spesifik dan kemudian memisahkan akar penyebabnya berdasarkan pendekatan permasalahan sehingga dapat mengurangi dan menghilangkan penyebab ketidaksesuaian produk (Hamza, 2015). Pada analisis ini, terdapat 4 faktor yang diamati, yaitu man, machine, material dan method. Keempat faktor tersebut memiliki subfaktor masing-masing. Penentuan subfaktor ini didasarkan pada data historis perusahaan, pengamatan secara langsung dan wawancara kepada bagian instalasi PG Kremboong. Berdasarkan hasil analisis yang telah dilakukan, didapatkan diagram fishbone seperti pada Gambar 3. 
Berdasarkan Gambar 3 diketahui terdapat 4 faktor yang mempengaruhi nilai OTE masih di bawah $85 \%$. Dari keempat faktor tersebut terdapat beberapa akar permasalahan yang mempengaruhi keempat faktor tersebut, yaitu:

\section{1) Man}

Faktor manusia merupakan salah satu penyebab tingkat OTE stasiun PG Kremboong di bawah $85 \%$. Faktor manusia tersebut diantaranya dipengaruhi oleh pekerja yang kurang disiplin dalam mempersiapkan peralatan, ketidaktahuan pekerja mengenai proses maintenance, dan pekerja masih melakukan kegiatan yang tidak produktif seperti mengobrol.

\section{2) Machine}

Kegiatan produksi di PG Kremboong berlangsung selama 24 jam dan terbagi dalam 3 shift kerja. Kegiatan produksi yang berjalan continue dan umur pabrik yang sudah sangat tua menjadi salah satu akar penyebab nilai OTE yang didapat masih dibawah $85 \%$.

\section{3) Material}

Kebutuhan material bahan baku tidak terpenuhi dikarenakan lahan perkebunan tebu yang menyempit dan banyak bermunculan PG baru yang menyebabkan PG Kremboong kekurangan pasokan tebu yang sesuai standar.

\section{4) Method}

Salah satu akar penyebab nilai OTE stasiun gilingan di bawah $85 \%$ adalah metode Quality Control bahan baku kurang ketat, tidak ada waktu standar perbaikan yang ditetapkan, dan kurangnya pengawasan kinerja mesin menyebabkan perencanaan perbaikan seperti preventif maintenance tidak maksimal.

$$
\begin{aligned}
& \mathrm{OTE}=\frac{\min \left\{\min _{i=1,2, \ldots, n=1}\left\{O E E_{(i)} X R_{t h(i)} X \prod_{j=i+1}^{n} Q_{e f f(j)}\right\}, O E E_{(n)} X R_{t h(n)}\right\}}{\min _{i=1,2, \ldots, n}\left\{R_{t h(i)}\right\}}
\end{aligned}
$$

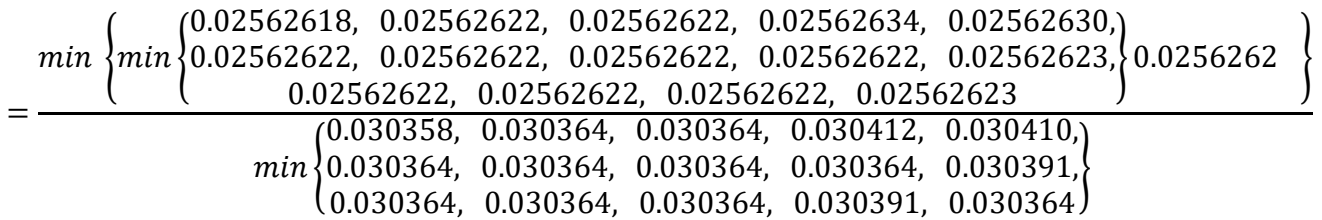

$$
\begin{aligned}
& =\frac{0.025626}{0.030358}=84,41 \%
\end{aligned}
$$

Tabel 1. Data downtime mesin

\begin{tabular}{lccc}
\hline Nama Mesin & Setup (Menit) & Delay (Menit) & Down time (Menit) \\
\hline Cane unloading crane & 0 & 5.040 & 0 \\
Meja tebu & 360 & 4.900 & 140 \\
CCR I & 360 & 5.040 & 0 \\
Cane cutter I & 360 & 4.900 & 350 \\
Cane cutter II & 360 & 4.900 & 345 \\
Unigrator & 360 & 5.040 & 0 \\
CCR II & 360 & 5.040 & 0 \\
Mesin Giling I & 360 & 5.040 & 0 \\
IMC I & 0 & 5.040 & 0 \\
Mesin Giling II & 360 & 5.020 & 140 \\
IMC II & 0 & 5.040 & 0 \\
Mesin Giling III & 360 & 5.040 & 0 \\
IMC III & 0 & 5.040 & 0 \\
Mesin Giling IV & 360 & 5.040 & 120 \\
Rotary Cush-Cush & 0 & 5.040 & 0 \\
\hline
\end{tabular}


Tabel 2. Data ICT dan ACT

\begin{tabular}{clcc}
\hline No. & Nama Mesin & ICT (Menit/ Ton) & ACT (Menit/ Ton) \\
\hline 1 & Cane unloading crane & 0,5490 & 0,6250 \\
2 & Meja tebu & 0,5488 & 0,6241 \\
3 & CCR I & 0,5488 & 0,6242 \\
4 & Cane cutter I & 0,5480 & 0,6250 \\
5 & Cane cutter II & 0,5480 & 0,6250 \\
6 & Unigrator & 0,5488 & 0,6250 \\
7 & CCR II & 0,5488 & 0,6250 \\
8 & Mesin Giling I & 0,5488 & 0,6245 \\
9 & IMC I & 0,5488 & 0,6250 \\
10 & Mesin Giling II & 0,5484 & 0,6250 \\
11 & IMC II & 0,5488 & 0,6250 \\
12 & Mesin Giling III & 0,5488 & 0,6245 \\
13 & IMC III & 0,5488 & 0,6250 \\
14 & Mesin Giling IV & 0,5484 & 0,6250 \\
15 & Rotary Cush-Cush & 0,5488 & 0,6241 \\
\hline
\end{tabular}

Tabel 3. Data hasil perhitungan total time available, planned downtime, loading time, operating time, ICT dan processed amount

\begin{tabular}{lcccccc}
\hline Nama Mesin & $\begin{array}{c}\text { Total } \\
\text { Time } \\
\text { Available } \\
\text { (Menit) }\end{array}$ & $\begin{array}{c}\text { Planned } \\
\text { Downtime } \\
\text { (Menit) }\end{array}$ & $\begin{array}{c}\text { Loading } \\
\text { time } \\
\text { (Menit) }\end{array}$ & $\begin{array}{c}\text { Operating } \\
\text { time } \\
\text { (Menit) }\end{array}$ & $\begin{array}{c}\text { ICT } \\
\text { (menit/ } \\
\text { ton) }\end{array}$ & $\begin{array}{c}\text { Processed } \\
\text { amount } \\
\text { (ton) }\end{array}$ \\
\hline Cane unloading & 155.100 & 4.400 & 150.700 & 145.660 & 0,54900 & 231.712 \\
crane & 155.100 & 4.400 & 150.700 & 144.840 & 0,54889 & 231.712 \\
Meja tebu & 155.100 & 4.400 & 150.700 & 144.840 & 0,54889 & 231.712 \\
CCR I & 155.100 & 4.400 & 150.700 & 144.630 & 0,54804 & 231.712 \\
Cane cutter I & 155.100 & 4.400 & 150.700 & 144.635 & 0,54806 & 231.712 \\
Cane cutter II & 155.100 & 4.400 & 150.700 & 144.840 & 0,54889 & 231.712 \\
Unigrator & 155.100 & 4.400 & 150.700 & 144.840 & 0,54889 & 231.712 \\
CCR II & 155.100 & 4.400 & 150.700 & 144.840 & 0,54889 & 231.712 \\
Mesin Giling I & 155.100 & 4.400 & 150.700 & 144.840 & 0,54889 & 231.712 \\
IMC I & 155.100 & 4.400 & 150.700 & 144.720 & 0,54840 & 231.712 \\
Mesin Giling II & 155.100 & 4.400 & 150.700 & 144.840 & 0,54889 & 231.712 \\
IMC II & 155.100 & 4.400 & 150.700 & 144.840 & 0,54889 & 231.712 \\
Mesin Giling III & 155.100 & 4.400 & 150.700 & 144.840 & 0,54889 & 231.712 \\
IMC III & 155.100 & 4.400 & 150.700 & 144.720 & 0,54840 & 231.712 \\
Mesin Giling IV & & & & & \\
Rotary Cush- & 155.100 & 4.400 & 150.700 & 144.840 & 0,54889 & 231.712 \\
Cush & & & & & & \\
\hline
\end{tabular}


Jurnal Teknologi Pertanian Vol. 22 No.1 [April 2021] 57-68

Pengukuran Efektivitas Mesin Produksi Gula (Kurniawan dkk)

Tabel 4. Data hasil perhitungan $\mathrm{A}_{\text {eff }}, \mathrm{P}_{\text {eff }}, \mathrm{Q}_{\text {eff, }}$, dan OEE

\begin{tabular}{lcccc}
\hline Nama Mesin & $\mathbf{A}_{\text {eff }} \mathbf{( \% )}$ & $\mathbf{P}_{\text {eff }} \mathbf{( \% )}$ & $\mathbf{Q}_{\text {eff }} \mathbf{( \% )}$ & OEE (\%) \\
\hline Cane unloading crane & 96,66 & 87,33 & 100 & 84,413 \\
Meja tebu & 96,11 & 87,81 & 100 & 84,396 \\
CCR I & 96,11 & 87,81 & 100 & 84,396 \\
Cane cutter I & 95,97 & 87,80 & 100 & 84,265 \\
Cane cutter II & 95,98 & 87,80 & 100 & 84,268 \\
Unigrator & 96,11 & 87,81 & 100 & 84,396 \\
CCR II & 96,11 & 87,81 & 100 & 84,396 \\
Mesin Giling I & 96,11 & 87,81 & 100 & 84,396 \\
IMC I & 96,11 & 87,81 & 100 & 84,396 \\
Mesin Giling II & 96,03 & 87,81 & 100 & 84,321 \\
IMC II & 96,11 & 87,81 & 100 & 84,396 \\
Mesin Giling III & 96,11 & 87,81 & 100 & 84,396 \\
IMC III & 96,11 & 87,81 & 100 & 84,396 \\
Mesin Giling IV & 96,03 & 87,81 & 100 & 84,321 \\
Rotary Cush-Cush & 96,11 & 87,81 & 100 & 84,396 \\
\hline
\end{tabular}

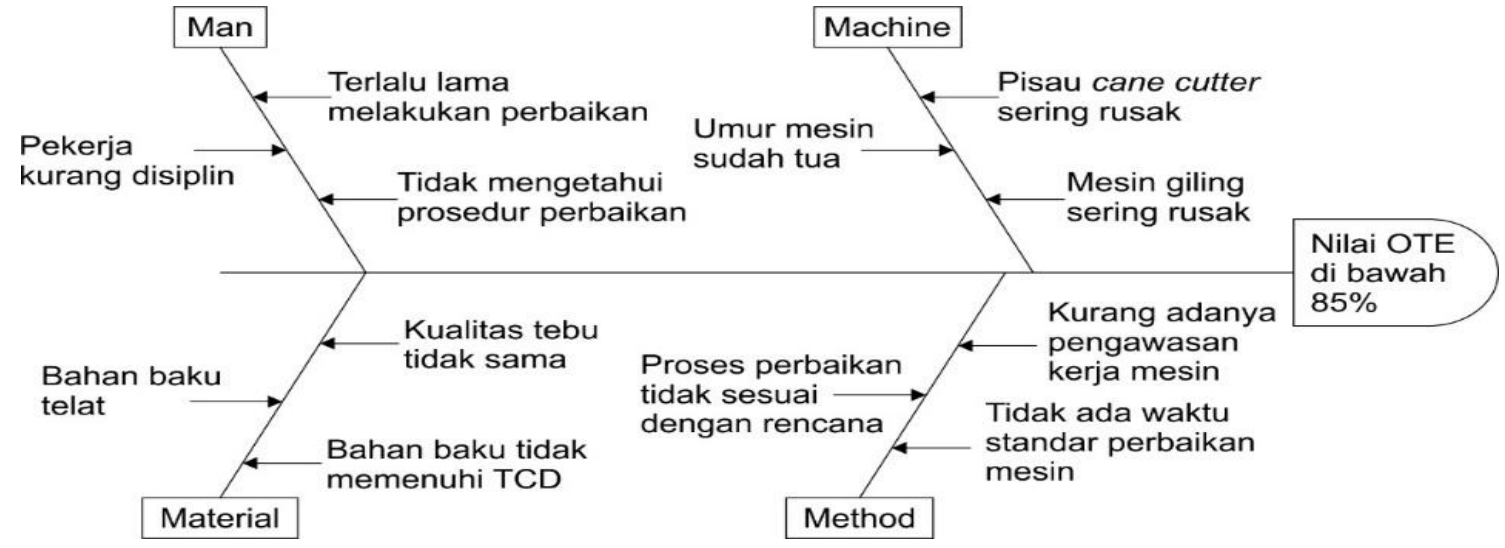

Gambar 3. Diagram Fishbone Nilai OTE dibawah 85\%

Identifikasi Alternatif Strategi Peningkatan Efektivitas Mesin dengan Metode Analytical Hierarchy Process (AHP)

Untuk mendapatkan alternatif solusi yang terbaik, perlu dilakukan pembobotan pada setiap faktor maupun subfaktor. Pembobotan dilakukan dengan menyebarkan kuesioner kepada responden pakar yang menjadi bagian dari penelitian terkait kondisi aktivitas mesin produksi. Pemilihan responden ditentukan berdasarkan kredibilitas dan kompetensi responden. Struktur hirarki keputusan dapat dilihat pada Gambar 4.

\section{a. Bobot level faktor}

Berdasarkan kasus yang terjadi, terdapat empat faktor yang Mempengaruhi peningkatan efektivitas produksi. Faktor yang memiliki bobot tertinggi merupakan faktor yang paling berpengaruh dalam peningkatan efektivitas produksi. Hasil pengolahan data yang dapat dilihat pada Tabel 5 .

Tabel 5. Prioritas faktor meningkatkan efektivitas stasiun giling PG Kremboong

\begin{tabular}{clcc}
\hline No. & Faktor & Bobot & Peringkat \\
\hline 1 & Man & 0,063 & 4 \\
2 & Machine & 0,118 & 3 \\
3 & Material & 0,543 & 1 \\
4 & Method & 0,275 & 2 \\
\hline \multicolumn{2}{l}{ Rasio Inkonsistensi } & 0,08 & \\
\hline
\end{tabular}


Berdasarkan hasil tersebut, material merupakan faktor yang paling berpengaruh terhadap peningkatan efektivitas produksi dengan bobot 0,543 . Faktor yang berpengaruh selanjutnya adalah method di peringkat kedua dengan bobot 0,275 , machine di peringkat ketiga dengan bobot 0,118 , dan man di peringkat keempat dengan bobot 0,063 . Rasio inkonsistensi sebesar 0,08 yang berarti hasil dinyatakan valid karena rasio inkonsistensinya di bawah 0,1 . Faktor material merupakan faktor yang memiliki bobot paling tinggi sehingga paling berpengaruh dalam meningkatkan efektivitas produksi. Maka dari itu, permasalahan terkait bahan baku memiliki prioritas tinggi yang harus segera diselesaikan oleh perusahaan. Menurut Robyanto et al. (2013), setiap perusahaan harus mengadakan persediaan bahan baku, karena tanpa adanya persediaan bahan baku akan mengakibatkan terganggunya proses produksi dan tidak memperoleh keuntungan yang maksimal. Persediaan yang berlebihan atau sebaliknya dapat merugikan perusahaan. Selain itu, baik buruknya kualitas bahan baku juga akan berpengaruh pada kinerja mesin.

\section{b. Bobot level alternatif strategi}

Berdasarkan perhitungan terdapat 3 alternatif perbaikan untuk meningkatkan efektivitas produksi stasiun giling PG Kremboong. Alternatif strategi yang memiliki bobot tertinggi merupakan alternatif solusi yang menjadi prioritas. Bobot alternatif strategi peningkatan efektivitas produksi dapat dilihat pada Tabel 6 .

Berdasarkan hasil tersebut, perbaikan perencanaan produksi merupakan strategi yang dianggap berpengaruh dalam meningkatkan efektivitas produksi dengan bobot 0,606 . Strategi selanjutnya yaitu peningkatan pengawasan dan pengecekan mesin dengan bobot 0,234, dan memberikan pelatihan perbaikan mesin di peringkat ketiga dengan bobot 0,161. Rasio Inkonsistensi sebesar 0,05 yang berarti hasil dinyatakan valid karena rasio inkonsistensinya dibawah 0,1. Menurut Ristumadin (2015), dalam suatu perusahaan yang memiliki tipe produksi massal, yang melibatkan sejumlah besar komponen yang harus dirakit, perencanaan produksi memegang peranan yang penting dalam membuat penjadwalan produksi (production schedule) terutama dalam masalah pengaturan operasi-operasi atau penugasan kerja yang harus dilakukan.

Berdasarkan nilai OTE yang diperoleh, efektivitas stasiun PG Kremboong masih di bawah $85 \%$. Hal ini menunjukkan bahwa proses produksi belum berjalan optimal. Guna meningkatkan efektivitas produksi dipengaruhi oleh 4 faktor yaitu man, machine, material, dan method. Perbaikan perencanaan produksi merupakan alternatif strategi pertama yang dapat diterapkan. Berdasarkan pembobotan antar faktor, faktor material merupakan faktor yang paling berpengaruh dalam meningkatkan efektivitas produksi. Kebutuhan tebu PG Kremboong per harinya mencapai 2500 ton. Namun kenyataannya, perusahaan hanya menggiling tebu dengan rata-rata 2186 ton. Tidak tercapainya TCD tersebut dipengaruhi oleh lahan perkebunan tebu yang menyempit dan banyak bermunculan PG baru yang menyebabkan PG Kremboong kekurangan pasokan tebu. Untuk mengatasi hal tersebut, perlu diadakan perencanaan produksi terlebih pada bagian bahan baku. Baroto (2002) dan Nicholds et al. (2018) menyatakan bahwa ada beberapa hal yang perlu diperhatikan dalam persediaan bahan baku untuk kegiatan operasional atau kegiatan produksi suatu unit usaha, antara lain biaya dalam pembelian bahan baku (economic order quantity), waktu pemesanan kembali (reorder point), dan persediaan pengaman (safety stock). Selain itu, PG Kremboong hendaknya membangun relasi lebih intensif dengan petani tebu rakyat sebagai mitra kerja melalui pertemuan secara berkala, lebih transparansi dalam perhitungan rendemen, dan memperbaiki pola kemitraan. Hal tersebut bertujuan supaya petani tebu rakyat menggiling tebunya di PG Kremboong untuk menambah jumlah pasokan bahan baku tebu di PG Kremboong. Menurut Andoyo dan Wibowo (2019), relasi yang baik antara pabrik gula dan pertani tebu dapat meningkatkan loyalitas serta timbul suatu kepercayaan antara petani tebu rakyat dengan pabrik gula.

Alternatif strategi yang kedua yaitu peningkatan pengawasan dan pengecekan mesin. Pengawasan dan pengecekan stasiun gilingan dilakukan setiap jamnya dengan mencatat jumlah tebu yang digiling. Pengecekan dan pengawasan yang dilakukan sudah baik, namun dapat ditingkatkan dengan menambahkan informasi mengenai kondisi mesin yang sedang beroperasi. Dengan pengecekan dan pengawasan tersebut, downtime dapat diminimalisir atau bahkan dapat dihilangkan dan proses perbaikan juga akan berjalan lebih karena dapat memprediksi kemungkinan kerusakan yang terjadi. Menurut Ristyowati et al. (2017), memberi arahan dan 
pengawasan terhadap pekerja dan melakukan pemeriksaan atau pengecekan mesin secara berkala dapat meminimasi kerugian yang terjadi pada proses produksi.

Alternatif strategi yang terakhir yaitu memberikan pelatihan perbaikan mesin. Pelatihan yang dilakukan di PG Kremboong dilakukan 3-4 kali setiap tahunnya. Jumlah tersebut dirasa sudah cukup, namun untuk meminimalisir kerusakan mesin dan perbaikan mesin yang terlalu lama, dalam pelatihan tersebut dapat ditetapkan dan dijelaskan waktu standar perbaikan mesin. Sehingga hal tersebut dapat menjadi patokan ketika terjadi kerusakan yang sama. Menurut Ristyowati et al. (2017), tindakan yang kemungkinan bisa dilakukan untuk perbaikan adalah dengan memberikan pelatihan kepada pekerja/operator untuk penyetaraan tingkatan keterampilan dan standar kerja agar lebih memahami dan mengetahui kegiatan proses yang benar.

Tabel 6. Bobot alternatif strategi peningkatan efektivitas produksi

\begin{tabular}{clcc}
\hline No. & Faktor & Bobot & Peringkat \\
\hline 1 & Perbaikan perencanaan produksi & 0,606 & 1 \\
2 & Peningkatan pengawasan dan pengecekan mesin & 0,234 & 2 \\
3 & Memberikan pelatihan perbaikan mesin & 0,161 & 3 \\
\hline \multicolumn{2}{l}{ Rasio Inkonsistensi $\quad 0,06$} &
\end{tabular}

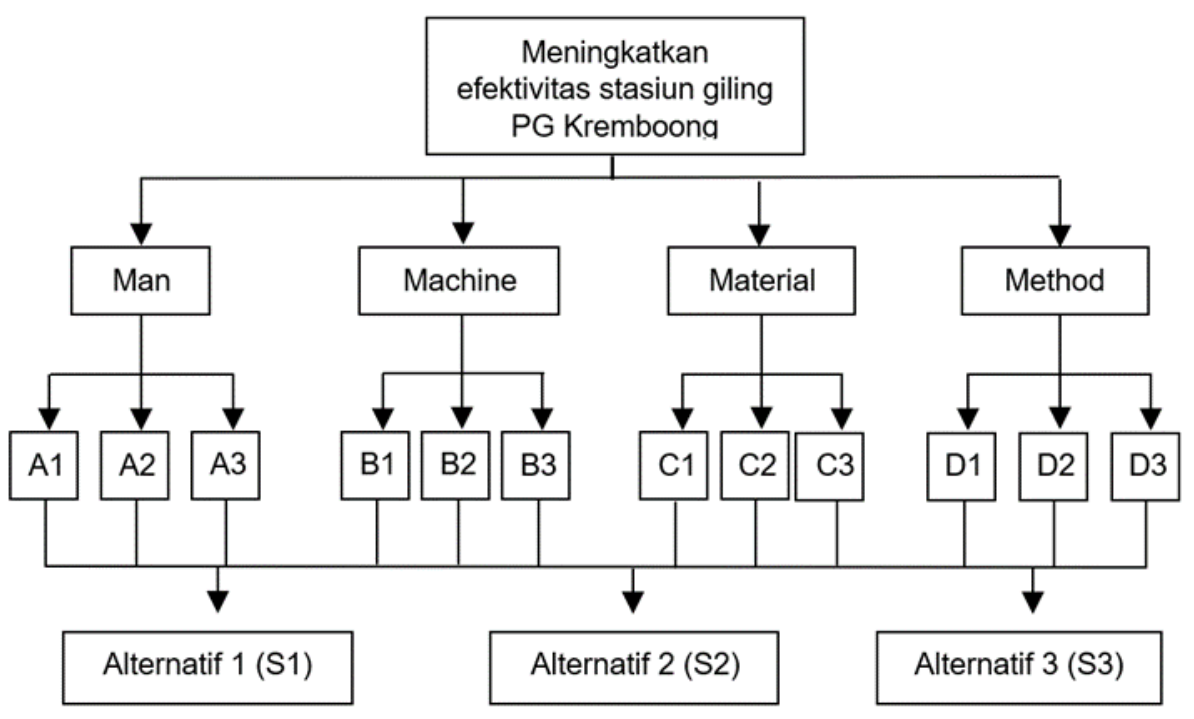

Gambar 4. Struktur hirarki 


\section{SIMPULAN}

Hasil penelitian menunjukkan nilai OTE sebesar 84,41\% dengan bottleneck indicator sebesar 0,0256 artinya performa maintenance perusahaan masih dalam kondisi bagus. Rata-rata kerugian yang terjadi pada setiap mesin yaitu breakdown losses $0,048 \%$, setup and adjustment losses $0,159 \%$, idle and minor stoppages $12,127 \%$, dan reduced speed losses $11,749 \%$. Faktor yang menjadi prioritas utama pada metode AHP yaitu material $(0,543)$, method $(0,275)$, machine $(0,118)$ dan man $(0,063)$. Prioritas alternatif strategi perbaikan untuk meningkatkan efektivitas stasiun giling PG Kremboong terdiri atas perbaikan perencanaan produksi $(0,606)$, peningkatan pengawasan dan pengecekan mesin $(0,234)$, dan memberikan pelatihan perbaikan mesin $(0,161)$.

\section{DAFTAR PUSTAKA}

Andoyo, -S., Wibowo, -R., 2019. Analisis pengendalian persediaan bahan baku tebu di PG Semboro PT. Perkebunan Nusantara XI kabupaten Jember. Jurnal Ekonomi Pertanian dan Agribisnis. 3, 10-20. https://doi.org/10.21776/ub.jepa.2019.003 .01 .2

Baroto, T. 2002. Perencanaan dan Pengendalian Produksi. Ghalia Indonesia, Jakarta

Cahyati, -S., Pramudya, -B., Pertiwi, -S., Herodian, -S., 2011. Identifikasi kekritisan komponen pada lini produksi pabrik gula tebu menggunakan metode equipment criticality rating. Jurnal Keteknikan Pertanian. 25(1), 7378.https://doi.org/10.19028/jtep.025.1.\%25p

Chikwendu, O, -C, Chima, A, -S., Edith, M, -C., 2020. The optimization of overall equipment effectiveness factors in a pharmaceutical company. Heliyon. 6(4), e03796. https://doi.org/10.1016/j.heliyon.2020.e03796

Hamza, A, -A., 2015. Analisa total productive Maintenance dengan menggunakan metode overall equipment effectiveness di PT. Karung Emas. MATRIK, Jurnal Manajemen dan Teknik Industri Produksi. 16, 33-50. http://dx.doi.org/10.30587/matrik.v16i1.550

Hardiyansyah, A, Singgih, ML. 2012. Perancangan Program Aplikasi Untuk Mengukur Performansi Sistem Produksi Dengan Metode Overall Throughput Effectiveness (OTE) dan Penjadwalan Preventive Maintenance. Skripsi. Institut Teknologi Sepuluh Nopember. Surabaya

Maknunah, L, -U., Achmadi, -F., Astuti, -R., 2016. Penerapan overall equipment effectiveness (OEE) untuk mengevaluasi kinerja mesineffectiveness. Jurnal Teknik Industri. 16, 41-50. mesin di stasiun giling pabrik gula Krebet II Malang. Jurnal Teknologi Industri Pertanian. 26, 189-198. https://journal.ipb.ac.id/index.php/jur naltin/article/view/14606

Nakajima, S. 1988. Introduction to TPM: Total Productive Maintenance, Eleventh P. ed. Productivity Press, New York

Nicholds, B, -A., Mo, J, -P., O'Rielly, -L., 2018. An integrated performance driven manufacturing management strategy based on overall system effectiveness. Computers in Industry. 97, 146-156. https://doi.org/10.1016/j.compind.2018.02.008

Ristumadin,-I., 2015. Analisa produktivitas dan efisiensi kerja dengan line balancing pada area lead connected. Jurnal PASTI, Penelitian dan Aplikasi Sistem \& Teknik Industri. 9, 300-310. https://publikasi.mercubuana.ac.id/index.php /pasti/article/view/493

Ristyowati, -T., Muhsin, -A., Nurani, P, -P., 2017. Minimasi waste pada aktivitas proses produksi dengan konsep lean manufacturing (studi kasus di PT. Sport Glove Indonesia). OPSI, Jurnal Optimasi Sistem Industri. 10(1), 85-96. https://doi.org/10.31315/opsi.v10i1.21 91

Robyanto, -C., Antara, -M., Dewi, -R., 2013. Analisis persediaan bahan baku tebu pada pabrik gula Pandji PT. Perkebunan Nusantara XI (Persero) Situbondo, Jawa Timur. E-Journal Agribisnis dan Agrowisata. 2, 23-31. https://ojs.unud.ac.id/index.php/JAA/arti cle/view/4920

Rochim, -A., Iskandar, 2015. Penentuan interval waktu optimum penggantian pisau cane cutter pada mesin cane cutter dengan pendekatan reliability di PT. Perkebunan Nusantara X (Persero) PG Kremboong. Jurnal Teknik Mesin. 1(1), 107-111. https://jurnalmahasiswa.unesa.ac.id/index.ph $\mathrm{p} / \mathrm{jtm}$-unesa/article/view/12768/11769

Schiraldi, M, -M, Varisco, -M., 2020. Overall equipment effectiveness: consistency of ISO standard with literature. Computers \& Industrial Engineering. 145, 106518.https://doi.org/10.1016/j.cie2020.106518

Sitompul, B, -G., Rinawati, D, -I., 2019. Analisis overall equipment effectiveness (OEE) pada mesin digester dan pendekatan 5 WHYS untuk perbaikan pada PT Toba Pulp Lestari, Tbk (studi Kasus: PT Toba Pulp Lestari, Tbk). Industrial Engineering Online Journal. 8, 1-10. https://ejournal3.undip.ac.id/index.php/ieoj /article/view/23258

Subiyanto., 2014. Analisis efektifitas mesin/alat pabrik gula menggunakan metode overall equipments https://doi.org/10.9744/jti.16.1.43-52 
Jurnal Teknologi Pertanian Vol. 22 No.1 [April 2021] 57-68

Pengukuran Efektivitas Mesin Produksi Gula (Kurniawan dkk)

Tayal, -A., Kalsi, N, -S., 2021. Review on effectiveness improvement by application of the lean tool in an industry. Materialstoday: Proceedings. 43(2), 1983-1991.

https://doi.org/10.1016/j.matpr.2020.11.431 